\title{
¿DIFERENTES PERO IGUALES? EL MANDATO \\ DE LOS SENADORES DE DESIGNACIÓN AUTONÓMICA Y LA STC 123/2017
}

\author{
Different but Equals? The mandate of the Senators \\ of autonomic designation and the STC 123/2017
}

\author{
MARÍA GARROTE DE MARCOS \\ Universidad Complutense \\ magarrot@ucm.es
}

Cómo citar/Citation

Garrote de Marcos, M. (2019)

¿Diferentes pero iguales? El mandato de los senadores de designación

autonómica y la STC 123/2017

Revista Española de Derecho Constitucional, 117, 277-309.

doi: https://doi.org/10.18042/cepc/redc.117.09

\section{Resumen}

El presente trabajo analiza la figura de los senadores autonómicos en el contexto institucional del sistema bicameral espańol. Se indaga sobre la capacidad de estos representantes para reforzar el carácter territorial de la representación atribuida al Senado. El examen de la trascendental STC 123/2017, de 2 de noviembre, que resuelve el recurso de inconstitucionalidad contra la ley valenciana de designación de senadores, sirve como pretexto para delimitar con más precisión los contornos del mandato de estos senadores. La sentencia confirma algunas evidencias, pero también deja algunas cuestiones por resolver. Ello permite plantear algunas reflexiones sobre el cometido y significación de estos senadores en el escenario político e institucional del parlamentarismo español, en un momento de cambios y transformaciones.

\section{Palabras clave}

Senadores autonómicos; Senado; mandato; representación territorial; revocación. 


\begin{abstract}
This paper analyses the figure of the regional senators in the institutional context of the Spanish bicameral system. The capacity of these representatives to strengthen the territorial nature of the representation attributed to the Senate is investigated. The examination of the transcendental STC 123/2017, of November 2, which resolves the appeal of unconstitutionality against the Valencian law of appointment of senators serves as a pretext to more precisely delimit the contours of the mandate of these senators. The ruling confirms some evidence but also leaves some issues to be resolved. This allows us to raise some reflections on the role and significance of these senators in the political and institutional scenario of Spanish parliamentarism, at a time of changes and transformations.
\end{abstract}

\title{
Keywords
}

Regional senators, Senate, mandate, territorial representation; recall. 


\section{SUMARIO}

I. EL SENADO COMO VANO INTENTO DE CÁMARA DE REPRESENTACIÓN TERRITORIAL. II. LOS SENADORES DE DESIGNACIÓN AUTONÓMICA. LA EVOLUCIÓN DE UNA FIGURA REPRESENTATIVA PECULIAR. III. LA STC 123/2017: ¿̇LA REAFIRMACIÓN DEL ESTATUS TRADICIONAL DE LOS SENADORES AUTONÓMICOS?: 1. Breve análisis de la Ley 10/2016, de 28 de octubre. 2. La STC 123/2017, de 2 de noviembre. IV. REFLEXIONES FINALES EN TORNO A LA FIGURA DEL SENADOR AUTONÓMICO Y POSIBILIDADES DE APERTURA. BibLIOGRAFÍA.

Tras más de cuarenta años de régimen democrático en España pocas instituciones han escapado del análisis crítico y casi todas ellas han sido objeto de diferentes propuestas de reforma, llegando incluso a cuestionarse su necesidad o viabilidad. El Senado es, quizá, la institución que ha atraído más atención desde los comienzos de su andadura constitucional. Ha sido el centro de muchos debates académicos y políticos y su encaje en el entramado institucional se ha sometido a permanente revisión, en un intento por dotar a la Cámara Alta de una mayor representatividad territorial. Los senadores de designación autonómica como categoría de análisis ofrecen considerable interés para comprender el alcance de la representación territorial atribuida al Senado. Sobre ellos se pueden proyectar reflexiones y propuestas que contribuyan a dotar de coherencia a una Cámara que no acaba de encontrar su sitio en la España de las autonomías del siglo XXI.

Desde hace unos años la figura de los senadores autonómicos ha adquirido una importante significación política provocada por la irrupción de nuevas fuerzas políticas y de nuevos - y más fragmentados - sistemas de partidos en el ámbito autonómico y por la designación cada vez más frecuente de personalidades políticas de considerable proyección y relevancia para el cargo de senador. El mundo del derecho no ha sido ajeno a estas transformaciones y es posible confirmar una evolución en el régimen jurídico de estos senadores, desde las reformas estatutarias de 2005 en adelante, que ha provocado la revisión de su normativa reguladora en casi todas las comunidades autónomas. Una de estas reformas es la que ha provocado el pronunciamiento del Tribunal Constitucional en la STC 123/2017, de 2 de noviembre, sobre la Ley de designación de senadores en representación de la Comunidad Valenciana, pronunciamiento que resulta de extraordinario interés, y que nos da pie para abordar algunas cuestiones relativas al mandato de estos parlamentarios en un 
contexto político, social e incluso generacional muy diferente al que alumbró su diseño institucional en los años ochenta del pasado siglo.

\section{EL SENADO COMO VANO INTENTO DE CÁMARA DE REPRESENTACIÓN TERRITORIAL}

La definición del Senado como Cámara de representación territorial, contenida en el art. 69.1 CE, es quizá el precepto constitucional que ha recibido más críticas por parte de la doctrina, con la convicción unánime de que esa afirmación no se corresponde ni con su diseño institucional ni con la realidad política de la Cámara.

No cabe duda de que la representación territorial atribuida al Senado se expresa fundamentalmente en la figura de los senadores autonómicos. Pero la representación territorial es una categoría conceptual controvertida. No es solo que no haya un acuerdo pacífico sobre lo que significa dicha representación, sino que en algunos casos se niega hasta su propia existencia (Garrido López, 2016; Caamaño Rodríguez, 2018). Lo único que no parece discutirse es que la noción de representación territorial surge en el contexto de Estados federales y está vinculada a la existencia de una segunda Cámara. De hecho, hablar de representación territorial solo tiene sentido en los Estados compuestos, donde existen entidades susceptibles de representación política autónoma y diferenciada de la representación general de la población en su conjunto (Alberti Rovira, 2004: 4).

En todo caso, la representación territorial se desenvuelve conjuntamente con la representación general o política, pero esta dualidad no implica ignorar la defensa de los intereses generales de los ciudadanos, sino reconocer que «existen también unos intereses territoriales singulares, que se vinculan a un tipo específico y distinto de representación, en la segunda Cámara» (Fernández-Carnicero, 2006: 335).

En esta línea, el Consejo de Estado (2009: 233-237) señala que solo cabe hablar de representación territorial cuando las diversas partes del territorio, diferenciadas de la comunidad política única, adquieren voz propia y se incorporan al proceso de formación de la voluntad del Estado. El cuerpo político queda representado así en su unidad y en su diversidad, cuya conjunción hace visible una representación plena. Esta idea no es otra que la de la representación compuesta, mecanismo que permite armonizar la representación del todo y la de cada una de las partes en los Estados compuestos. La representación compuesta es un concepto que, además de respetar la unidad de representación (pues la unidad se predica de la decisión y no tanto de la deliberación), 
permite incorporar dos ideas fundamentales: la integración de las partes en el todo y la limitación del poder (Alberti, 2004: 6 y ss.).

No obstante, para hacer presentes a las partes en las decisiones del Estado no siempre es necesaria - y casi nunca es suficiente- la existencia de una segunda Cámara que ostente la susodicha representación territorial. La participación de los entes territoriales en la decisión estatal no depende tanto de la existencia de una segunda Cámara "territorial», sino del sistema de partidos y de los elementos circunstanciales que explican su funcionamiento (Sáenz Royo, 2012: 185). Y es que no cabe representación territorial que no sea representación política ni existe representación política sin dimensión territorial (Garrido López, 2019: 76) ${ }^{1}$.

También se puede considerar que la territorialidad de la representación reposa sobre todo en la capacidad que tienen los entes territoriales para incidir en la designación de los integrantes de la Cámara. De esta forma, la diferencia entre la representación política y la representación especial es la diversa representatividad perseguida — ya sea general o específica-, entendida como los elementos valorativos que determinan una concreta forma de reclutamiento (Punset, 1980: 109). Cuando el modo de designación de los representantes está orientado a tutelar específicamente entidades territoriales la representación es territorial. Lo es porque la Constitución atribuye a los entes territoriales la designación de los parlamentarios en virtud de la representatividad específica perseguida (ibid.: 115).

Siendo esto así, la clave para valorar si estamos ante una verdadera representación territorial pasaría por examinar tres criterios: a) que sean las propias entidades territoriales las que designen a los representantes; b) que la Constitución atribuya a estas entidades territoriales la facultad de regular el procedimiento de designación, y c) que las entidades territoriales, a través de sus representantes, participen en la formación de la voluntad de la Cámara defendiendo o al menos manifestando los intereses de los entes territoriales en su propia esfera de competencias (ibid.: 113; Alonso de Antonio, 2005: 362-363).

Además, para la efectividad de esa representación territorial es indispensable contemplar las funciones que tiene atribuida la Cámara parlamentaria y su posición relativa con respecto a la otra en el mecanismo de decisión (Alberti, 2004: 17 y ss.).

En todo caso, la representación territorial atribuida a las segundas Cámaras puede revestir diferentes grados de intensidad, siendo determinante la

1 Como afirma Caamaño (2018: 69), «la democracia de partidos desliza a las segundas cámaras hacia la nada [...] no conozco a ningún senador sin ideología ni a ningún diputado sin territorio». 
naturaleza del mandato de los representantes territoriales. Y es precisamente la vinculación al mandato imperativo la que diferencia los dos modelos clásicos de Cámaras territoriales: modelo Senado (mandato libre) o modelo Consejo (mandato imperativo).

Cuando la representación territorial se articula sobre la base de una Cámara tipo Senado, la participación de las entidades territoriales en la formación de la voluntad de Estado se concreta jurídicamente en su poder de designación. La relación interorgánica en estos casos adquiere «el carácter de vectorial y consuntiva, de suerte que la facultad de designación se agota en el acto mismo de su ejercicio» (Camaaño, 1991: 194).

No es una novedad sostener que el Senado español no encaja completamente en la categoría de Cámara de representación territorial.

Como es sabido, la redacción del art. 69 CE sufrió diversas versiones durante los debates constituyentes (Fernández Segado, 1984; Aja y Arbós, 1980; García-Escudero 1995: 71-108). En el anteproyecto inicial el Senado fue concebido como una Cámara de representación autonómica, pues se reconocía que era la Cámara que representa a los «territorios autónomos». Los senadores serían elegidos por las Asambleas legislativas de los territorios autónomos y también, pero solo en una pequeña parte, por el Congreso de los Diputados. La elección se haría entre los miembros de la Asamblea, por un período igual al de su propia legislatura, con arreglo a un sistema de representación proporcional y de manera que se asegurara la representación de las diversas áreas del territorio ${ }^{2}$.

El Informe de la Ponencia rectifica esta composición del Senado y se limita a señalar que estará compuesto por representantes de las distintas entidades territoriales, dejando su concreción a una ley orgánica posterior. Más adelante, la Comisión de Asuntos Constitucionales del Congreso de los Diputados aprobó una enmienda en la que el Senado quedaba configurado como una Cámara esencialmente de representación provincial, adoptando para ello un modelo muy semejante al de la Ley para la Reforma Política.

A su paso por el Senado y por la posterior Comisión Mixta, la configuración definitiva de la Cámara Alta sufrió notables modificaciones que añadieron algunos matices de auténtica representación territorial — autonómica一, pero continuaba siendo una Cámara de base mayoritariamente provincial. Fue entonces cuando se incorporó también la declaración del Senado como Cámara de representación territorial.

La figura de los senadores designados por las comunidades autónomas fue uno de los aspectos más cambiantes, con una configuración diferente

2 BOCG, Congreso de los Diputados, núm. 44, de 5 de enero de 1978, p. 679 
casi en cada lectura del texto. Pero fue en la tramitación en el Senado donde se acabó perfilando el apartado 5 del art. 69, tal y como lo recoge la Constitución. El apartado 2 del art. 64 del texto que fue aprobado en el Congreso de los Diputados preveía que cada comunidad autónoma propusiera dos candidatos a senadores - uno solo en el caso de comunidades autónomas uniprovinciales - que serían nombrados por el rey, de acuerdo con sus estatutos y en los términos que estableciera una ley orgánica ${ }^{3}$. En el Dictamen de la Comisión de Constitución del Senado se introducen dos importantes cambios ${ }^{4}$. En primer lugar, se atribuye a las comunidades autónomas la designación de los senadores, no la mera propuesta para su posterior nombramiento por el rey. Además, se introduce un criterio poblacional para determinar el número de senadores adicionales que corresponde a cada comunidad autónoma, a razón de uno por cada millón de habitantes. La Comisión mixta modificó su redacción y clarificó algunos aspectos: se suprime la referencia a una ley orgánica. Además, se precisa cuál es el órgano encargado de la designación, cuestión esta de enorme relevancia y que contribuye a dotar de cierta uniformidad al régimen de designación de estos senadores. Por último, se incluye la exigencia de representación proporcional, que ya estaba presente en el anteproyecto. En los términos en los que finalmente queda redactado el artículo esta exigencia de proporcionalidad se demostrará en ocasiones inútil cuando solo hay un senador a designar, o al menos problemática, cuando son dos.

De esta manera, la vacilante redacción del art. 69.5 ofrecía muy pocas certezas y muchas incertidumbres. Entre las certezas, que todas las comunidades autónomas tendrían como mínimo un senador y que sería designado por la Asamblea o, en su defecto, por el órgano colegiado superior. Entre las incertidumbres, prácticamente todo lo demás. La necesidad de desarrollo normativo, al menos en los estatutos de autonomía y en los reglamentos de las Asambleas, predeterminó la heterogeneidad del marco regulador de estos senadores, pero al mismo tiempo se ha revelado como uno de los rasgos más elocuentes de la autonomía.

Las distintas versiones del art. 69 obedecieron, se ha dicho, a dos tipos de razones. Por una parte, la incertidumbre sobre el diseńo del modelo territorial que se preveía en el título VIII, y, por otra, los acuerdos a los que llegaron las dos principales fuerzas políticas (UCD y PSOE). Parece que estos acuerdos - de un modo muy semejante a lo que ocurrió con el sistema electoral del Congreso previsto en el art. $68 \mathrm{CE}$ - fueron los que finalmente determinaron

3 BOCG, Congreso de los Diputados, núm. 135, de 24 de julio de 1978, p. 2956

4 BOCG, Senado, núm. 157, de 6 de octubre de 1978, p. 3427. 
que se mantuviera una composición muy semejante a la prevista en la Ley para la Reforma Política (Aja y Arbós, 1980: 39).

Se ha calificado el resultado final como una fórmula del tipo «suma cero»: los sectores conservadores querían preservar un Senado de composición rural con funciones moderadoras; los progresistas estaban de acuerdo con ello siempre que no se le otorgaran funciones decisivas. Y de ahí surgió un Senado incoherente y disfuncional (De Carreras, 1996: 32), que incluso antes de su constitucionalización se encontraba en una búsqueda permanente de su identidad (Fernández Segado, 1984: 117), y que a la postre termina por no encajar en ningún modelo teórico.

Probablemente debido a su configuración constitucional, provisional a falta de concretarse el modelo autonómico, insuficiente en relación con los atributos genuinamente territoriales y que lo relega a una posición conscientemente irrelevante, el Senado es incapaz de asumir dicho papel. La principal razón por la que no es posible sostener el carácter territorial del Senado es su composición. En la actualidad, solo 57 de los 265 senadores (21,5\%) son designados por las asambleas de las comunidades autónomas, de modo que la inmensa mayoría de los senadores son elegidos por el mismo cuerpo electoral (dividido en circunscripciones provinciales) que elige a los diputados y además lo hace al mismo tiempo. No sorprende que los resultados electorales de ambas Cámaras tiendan a ser muy semejantes, y ello pese a que el sistema electoral de los senadores provinciales es diferente 5 . Con frecuencia, las mayorías que ostenta el Gobierno en el Congreso de los Diputados se han visto amplificadas en Senado.

Solo los senadores de designación autonómica podrían llevar incorporada una suerte de representatividad territorial que reúna las condiciones necesarias conforme a la construcción doctrinal de la representación territorial. Si bien las comunidades autónomas gozan de autonomía para regular el procedimiento de designación de estos representantes, su número es absolutamente insuficiente. Además, como detallaremos más adelante, su estatuto jurídico, idéntico al del resto de senadores, impide, al menos jurídicamente, atribuirles una representación diferente a la del resto de parlamentarios de las Cortes Generales, que es la del pueblo espańol (art. 66.1 CE).

Por otra parte, la regulación de los grupos territoriales en el Senado (art. $32 \mathrm{RS}$ ), cuya composición se abre a ambos tipos de senadores, no

5 Como es sabido, el sistema electoral para los senadores provinciales es un sistema mayoritario de voto limitado. El sistema electoral del Congreso de los Diputados, aun siendo proporcional, produce resultados muy parecidos a los del Senado por la reducida magnitud de la mayoría de las circunscripciones (Lago y Martínez i Coma, 2007: 159-178; Penadés y Urquizu, 2007: 17). 
consigue superar la primacía de los grupos políticos en el desenvolvimiento de la actividad parlamentaria, verdaderos protagonistas (Ripollés Serrano, 1993: 59; Saiz Arnaiz, 1995: 293). Tampoco ha sido satisfactoria la reforma del Reglamento del Senado de 1994, que buscaba específicamente potenciar el carácter territorial a través de la Comisión General de las Comunidades Autónomas (García Escudero, 1994). Dotada de una composición especial, se le atribuyeron numerosas funciones, además de prever un peculiar régimen de convocatorias y comparecencias con la participación de los Gobiernos de las comunidades autónomas. Sin embargo, las aspiraciones fueron pronto ensombrecidas por la reticente voluntad política que ha terminado por desaprovechar las oportunidades que su funcionamiento activo podría proporcionar.

Precisamente es el realismo de la política el que más dificulta la consideración del Senado como Cámara territorial. La alineación partidista de todos los senadores, incluidos los de designación autonómica, y su incorporación a los grupos políticos ideológicos, impide reconocerlos como portavoces de las demandas o defensores de los intereses del territorio por el que fueron elegidos.

Pero, incluso si eso no fuera así, tampoco existen mecanismos eficaces que permitan articular la participación específica de las comunidades autónomas en la formación de la voluntad del Estado. La regulación constitucional de las funciones de la Cámara Alta revela una posición secundaria y subordinada en la competencia legislativa y marginal en la función de control. No puede, por tanto, llevar la posición de las comunidades autónomas al Parlamento y hacerlas presentes en los procesos de decisión que se desarrollan en el mismo, incluso en los que se ven implicados intereses autonómicos de forma directa e inmediata (Alberti, 2004: 39-40; García-Escudero, 1995: 48-60; Garrido, 2019: 39-57).

No es de extrañar que las críticas a la configuración constitucional del Senado hayan sido continuas desde la aprobación de la Constitución y que se hayan planteado diversas reformas tanto desde el ámbito político como doctrinal. Casi todas ellas han tenido en común la necesidad de adecuar su composición y funciones a la condición de Cámara de representación territorial. No es posible recoger aquí la ingente cantidad de trabajos que se han publicado a este respecto, baste únicamente indicar que en relación con la composición del Senado se han barajado diversas opciones que combinan varios criterios $^{6}$. Lógicamente la opción por una u otra composición tiende a

6 Nos remitimos a la bibliografía recogida en García-Escudero (1995: 60-67) y Garrido López (2019: 66-100). Además, Gutiérrez Rodríguez (2004) proporciona un extenso análisis de los debates sobre la reforma del Senado. Puede resultar de utilidad consultar el Informe del Consejo de Estado sobre modificaciones de la Constitución española, de 16 
configurar un determinado tipo de representatividad, que indudablemente tendría consecuencias también en el plano funcional de la Cámara, pero que difícilmente podría soslayar la adscripción partidista de los senadores.

\section{LOS SENADORES DE DESIGNACIÓN AUTONÓMICA. LA EVOLUCIÓN DE UNA FIGURA REPRESENTATIVA PECULIAR}

Como hemos visto, la Constitución apenas menciona en su art. 69.5 unas mínimas pautas para proceder a la designación de los senadores autonómicos: «Las Comunidades Autónomas designarán además un Senador y otro más por cada millón de habitantes de su respectivo territorio. La designación corresponderá a la Asamblea legislativa o, en su defecto, al órgano colegiado superior de la Comunidad Autónoma, de acuerdo con lo que establezcan los Estatutos, que asegurarán, en todo caso, la adecuada representación proporcional».

El desarrollo de este artículo en la normativa estatal ha sido bastante conciso ya que es esta una materia que corresponde regular a las comunidades autónomas? ${ }^{7}$ El régimen jurídico de estos senadores adquiere, por tanto, cierta complejidad por la dispersión de fuentes normativas que lo regulan y la variedad de su contenido. Tempranamente, en la STC 40/1981, sobre la Ley de designación de Senadores representantes de Euskadi, el Tribunal Constitucional precisó algunas cuestiones sobre el marco normativo de la designación de estos senadores. En primer lugar, afirmó que la designación de los senadores de las comunidades autónomas «es un aspecto de la autonomía, dentro del marco de lo establecido por la Constitución (arts. 69.5 y 70.1) y por el respectivo Estatuto de Autonomía» (FJ 1d). En segundo lugar, la designación de

de febrero de 2006. El texto del informe y los debates académicos en torno al mismo se pueden encontrar en Rubio Llorente y Álvarez Junco (2006). También pueden consultarse el repertorio bibliográfico sobre este tema de Reviriego y Núñez (2006) y los que se encuentran albergados en la página web del Senado: https://bit.ly/2X5VvqW.

7 Así, las referencias que se recogen en el Reglamento del Senado se centran principalmente en el modo de perfeccionamiento de su condición de senadores y eventual cese (arts. 1, 12, 18 y 19), en su incorporación a los grupos parlamentarios (art. 28), incluidos los grupos territoriales (art. 32), y un especial tratamiento a los mismos en el funcionamiento de la Comisión General de las Comunidades Autónomas (art. 56 bis, ap. 1 y ap. 5). Por su parte la Ley Orgánica de Régimen Electoral General solo se refiere a los senadores de designación autonómica para aclarar en su art. 165.4 que el número concreto de senadores que corresponda a cada comunidad autónoma se determinará tomando como referencia el censo de población de derecho vigente en el momento de celebrarse las últimas elecciones generales al Senado. 
estos senadores presenta el rasgo diferencial de que es una elección de segundo grado en el seno de las Asambleas legislativas, de modo que el inciso "de acuerdo con lo que establezcan los Estatutos» confiere un «margen para precisar alguna condición directamente conectada con el carácter propio de dicha designación», pudiéndose remitir a una ley siempre que la ley «se mueva dentro de los límites que resultan de una conexión con el carácter específico de su designación» (FJ 3b).

Resumidamente puede decirse que todas las comunidades autónomas incluyen en sus respectivos estatutos de autonomía la mención a la designación de estos senadores entre las funciones encomendadas a la Asamblea, la mayoría sin mayor concreción ${ }^{8}$. En cambio, otros estatutos aluden específicamente a otras cuestiones, como la necesidad de ostentar la condición de diputado de la Asamblea, la vinculación del mandato de senador a la propia Asamblea ${ }^{9}$, o las eventuales comparecencias de los senadores ante la Cámara ${ }^{10}$.

Asimismo, y con toda lógica, los reglamentos parlamentarios autonómicos regulan el procedimiento de designación de los senadores, pero cada vez son más las comunidades autónomas que prefieren detallar su regulación en una ley en lugar de incluirla en el reglamentario parlamentario ${ }^{11}$. Ello ha sido criticado por algunos, por entender que se trata de la ejecución de una competencia de la Asamblea, y, por tanto, de una materia propiamente reglamentaria, con el riesgo añadido que puede comportar para la autonomía parlamentaria (Saiz Arnaiz, 1985: 159-160; García-Escudero, 1995: 131). Pese a todo, lo cierto es que once comunidades autónomas cuentan con una ley específica que regula la designación de los senadores, cuyo contenido en ocasiones repite el del reglamento parlamentario correspondiente. Junto con ello, también se han dictado normas que completan las disposiciones legales y reglamentarias en la materia, como las resoluciones de las presidencias en Andalucía, Aragón o Castilla-La Mancha ${ }^{12}$.

8 Asturias, Aragón, Castilla-La Mancha, Castilla León, Murcia, Galicia, País Vasco, Navarra.

9 Así lo prevén el EA Cantabria (art. 9); EA Extremadura (art. 16.2); EA Madrid (art. 16.3), y EA La Rioja (art.19.1).

10 Son los casos del EA Andalucía (art. 223); EA Baleares (art. 50); EA Cataluña (art. 179), y EA Canarias (art. $43 \mathrm{~d})$ ).

11 Se remiten a la ley de designación los reglamentos de Asturias, Cantabria, Castilla-La Mancha, Castilla León, Comunidad Valenciana, Murcia y La Rioja.

12 Véanse la Resolución de 9 de abril de 2008, de la Presidencia del Parlamento de Andalucía; la Resolución de la Presidencia de las Cortes de Aragón, de 20 de noviembre de 2013, y la Norma interpretativa de la Presidencia de las Cortes de Castilla-La Mancha, de 20 de noviembre de 2001. 
Esta diversidad de fuentes es una muestra evidente de la autonomía con la que se ha diseñado el mecanismo de designación de los senadores autonómicos, cuyo régimen jurídico incluye ciertos elementos esenciales, que serían los siguientes: a) número de senadores que corresponde a cada comunidad autónoma; b) requisitos de elegibilidad; c) procedimiento de presentación y selección de candidatos; d) votación; e) relaciones entre los senadores y la Asamblea designante, y f) extinción del mandato. No es posible detenerse ahora en cada uno de estos aspectos, que ya han sido tratados, entre otros, por García Escudero (1995), Cuenca (2003), Garrote (2017), Marañón (2018). Nos limitaremos a resaltar los cambios que se han desarrollado en alguno de estos puntos y las cuestiones que han sido controvertidas, lo que nos permitirá ofrecer una panorámica de la evolución de la figura de estos senadores.

El número de senadores autonómicos se ha incrementado desde la II legislatura (46) hasta la XII (58). En la XIII legislatura la cifra ha bajado a 57 por la pérdida de un senador en la Comunidad Valenciana. La determinación del número de senadores que elige cada comunidad autónoma no ha sido siempre pacífica (García Escudero, 1995: 179-183), hasta el punto de que desde 2007 el Senado viene publicando un acuerdo de su Diputación Permanente sobre el número de senadores a designar por las comunidades autónomas una vez que se convocan elecciones generales. Aun así, la indefinición del órgano competente para determinar dicho número provocó un incidente sobre el número de senadores que correspondía elegir a las Corts Valencianes para la XII legislatura, poniendo de relieve las disfunciones que pueden surgir ante la repetición de elecciones ${ }^{13}$.

Los senadores que designa cada comunidad autónoma, por orden decreciente son los siguientes: Andalucía, nueve; Cataluña, ocho; Comunidad de Madrid, siete; Comunidad Valenciana, cinco; Castilla y León, tres; Canarias, tres; Castilla-La Mancha, tres; Galicia, tres; País Vasco, tres; Aragón, dos; Asturias, dos; Baleares, dos; Extremadura, dos; Murcia, dos; Cantabria, uno; Navarra, uno, y La Rioja, uno. Como puede comprobarse, solo cuatro comunidades autónomas eligen más de tres senadores, lo cual pone de manifiesto la

13 En el tránsito de las elecciones generales de 20 diciembre de 2015 a las de 26 de junio de 2016, y con los datos que manejaba la Diputación Permanente del Senado, la Comunidad Valenciana perdería uno de los senadores de designación autonómica, con los consiguientes efectos sobre la vigencia del mandato de uno de los senadores designados. Todo ello dio lugar al «Informe que emiten los servicios jurídicos de Les Corts en relación con la cuestión planteada en el escrito remitido por la Presidencia del Senado a la Presidencia de les Corts en fecha 5 de mayo de 2016» (Pérez Gabaldón, 2019: 428). 
dificultad de cumplir con las exigencias de representación proporcional, máxime si se tiene en cuenta la tendencia a una mayor fragmentación en los Parlamentos autonómicos, donde cada vez hay más grupos parlamentarios.

En cuanto a los requisitos de elegibilidad conviene señalar, en primer lugar, que el TC en su Sentencia 40/1981 avaló la posibilidad de incluir condiciones de elegibilidad y causas de incompatibilidad más allá de las prescritas en el art. 70. $1 \mathrm{CE}$, que vendría a establecer un mínimo, «dando lugar a que la regulación del estatuto de los senadores designados por las Comunidades Autónomas no caiga íntegramente bajo la legislación electoral general» (FJ 1d). Exigir la condición política de miembro de la comunidad autónoma es la regla general en todas las comunidades autónomas.

En este punto se ha registrado una interesante evolución. La necesidad de ostentar la condición de diputado de la Asamblea autonómica para ser designado senador estaba presente con anterioridad en doce comunidades autónomas. Las recientes reformas llevadas a cabo, ya sea en los estatutos de autonomía, ya sea en las propias leyes de designación, han suprimido esta ligazón en Andalucía, Aragón, Baleares, Castilla-La Mancha, Castilla y León, Cataluña, Extremadura y Canarias. En la actualidad solo cuatro comunidades autónomas mantienen la necesidad de que el senador sea miembro de la Cámara, si bien en Extremadura se permite optar por mantener el escaño o dimitir ${ }^{14}$. De esta forma, la necesaria acumulación de mandatos solo se da en tres comunidades autónomas (Cantabria, La Rioja y Madrid), dos de las cuales eligen a un único senador. Algunos autores defienden esta vinculación por entender que potencia la representación territorial en el Senado (Asensi y Sevilla, 1986: 117; Elizalde, 1989: 131). Sin embargo, hay quien sostiene que dicha acumulación de mandatos supone una contradicción con la prohibición de mandato imperativo del art. 67.2 CE, que en esos supuestos goza de una menor garantía (Punset, 1983: 183). Sea como fuere, la tendencia a desvincular el mandato senatorial del de diputado autonómico ha supuesto una transformación en el régimen jurídico de los senadores, al preverse fórmulas de relación entre éstos y la Cámara designante que antes no eran necesarias.

El procedimiento de presentación, selección y votación de los candidatos es en muchos casos una mera cuestión de trámite. Sin embargo, dos puntos pueden resultar problemáticos. La exigencia de representación proporcional ha sido una cuestión controvertida que ha resuelto el Tribunal Constitucional flexibilizando el criterio de proporcionalidad, bastando que se evite la aplicación

14 Cantabria, (art. 9.8 EA, y art. 2.1 de la Ley electoral del Parlamento de Cantabria); Extremadura (art. 16.2.1 EA); Madrid, (art. 224 Reglamento de la Asamblea y art. 10. 8 EA), y La Rioja, (19.1.1 EA y 2.1. Ley electoral). 
pura y simple de un criterio mayoritario (SSTC 40/81, de 18 de diciembre; 75/1985, de 21 de junio, y 4/1992, de 13 de enero). La determinación del número de senadores que corresponde proponer a cada grupo parlamentario le corresponde a la Mesa, normalmente con el acuerdo del Junta de Portavoces, aunque a veces solo será oída (Marañón, 2018: 265).

Todas las comunidades autónomas prevén la intervención del Pleno, ya sea para votar a los senadores, ya sea para ratificar las propuestas (García-Escudero, 1995: 209-211; Cuenca, 2003: 150-151). Hasta ahora, no había ninguna duda de que la elección de las personas que resultarán elegidas correspondía a los grupos parlamentarios, aunque se prevean comparecencias previas (como en Andalucía o Cataluña) o que el acuerdo formal corresponda al Pleno, que no tendrá margen real de decisión (Navarro Marchante, 2018: 129).

Sin embargo, la votación fallida del candidato del grupo Socialistes i Units per Avançar en el Parlamento de Cataluña el 16 de mayo de 2019 ha supuesto un suceso inédito y sorprendente que, además, parece no tener fácil componenda. La votación de los senadores autonómicos en el Parlamento de Cataluña se realiza a partir de una propuesta conjunta de los candidatos, que es la que se somete a votación del Pleno. El sistema utilizado habitualmente es el de la votación electrónica, que permite votar sí, no o abstención. Ante la necesidad de votar a un único candidato (que venía a sustituir al anterior senador socialista José Montilla), se solicitó que la votación se realizara con papeletas (en las que solo es posible votar nombres, en blanco o abstenerse). La decisión de la Mesa del Parlamento de mantener la votación electrónica condujo al rechazo de la designación de Miquel Iceta como senador por 25 votos a favor, 65 en contra y 39 abstenciones. El grupo parlamentario Socialistes i Units per Avançar del Parlamento de Cataluña interpuso un recurso de amparo ante el TC impugnando directamente la decisión de la Mesa del Parlamento de Cataluña que desestimó la solicitud de que la votación se efectuara mediante papeletas, pero no se impugnó la decisión de no proponer a Iceta, adoptada por el Pleno ese mismo día. Dado que el sistema de votación electrónico es el que se utiliza habitualmente, en principio no parece que la Mesa haya vulnerado ningún derecho por decidir lo mismo que siempre ha decidido (Ruiz Robledo, 2019). El recurso de amparo fue admitido a trámite el 21 de mayo de 2019, pero se denegó la solicitud de suspensión de la decisión de la Mesa por constituir un acto ya ejecutado plenamente y haberse agotado sus efectos. Los recurrentes invocaron «el efecto indirecto que tiene la decisión del sistema de votación sobre el derecho de representación política de los diputados que conforman el grupo parlamentario por la situación de bloqueo que conlleva en la designación de un senador que a ellos corresponde proponer y 
la consecuente alteración que se produce en la conformación del Senado». Pero, a juicio del Tribunal, «esta argumentación identifica el perjuicio irreparable con la lesión alegada, por lo que se proyecta exclusivamente sobre el fondo de la cuestión planteada en la demanda» (ATC 65/2019, de 18 de junio).

Planteada en esos términos, parece que la demanda de amparo no tendrá mucho recorrido. Haría falta considerar que el acto objeto de impugnación produce un efecto indirecto que es el que puede lesionar el derecho fundamental a participar en los asuntos públicos (art. $23 \mathrm{CE}$ ). En efecto, si se entiende que existe una costumbre parlamentaria a favor de la aceptación de las propuestas y que el Pleno solo podría rechazarlas si el candidato estuviera incurso en una causa de inelegibilidad, el rechazo del candidato sin la suficiente motivación podría estar vulnerando el derecho del art. 23 CE (Ruiz Robledo, 2019).

En todo caso, este suceso pone en evidencia la verdadera realidad de la designación de los senadores en las comunidades autónomas; las maniobras políticas a las que se somete lo que debería ser un mecanismo transparente y democrático convierten a veces el proceso en una disputa política ajena totalmente a su finalidad legítima ${ }^{15}$.

Y es que, desde las elecciones autonómicas de 2015, la mayor fragmentación de los parlamentos autonómicos ha favorecido que pequeños partidos obtengan presencia en el Senado mediante esta vía de designación. A veces por derecho propio, pero en ocasiones como parte de un pacto político. Tras las elecciones autonómicas de 2019 han sido designados como senadores candidatos de partidos políticos con una representación exigua en la Cámara autonómica, que, de no ser por el pacto con otras fuerzas políticas mayoritarias, no habrían podido ser designados como senadores, en aplicación del principio de proporcionalidad. Esto no solo podría contravenir la exigencia constitucional de proporcionalidad, en puro respeto a la voluntad expresada por los electores de la comunidad autónoma, sino que, además, refleja hasta qué punto la coyuntura política regional se traslada al ámbito de

15 Hay algunos casos recientes que no dejan de sorprender. La selección del candidato del PP Javier Maroto para ser designado senador por las Cortes de Castilla y León provocó muchas críticas, habida cuenta de su previa candidatura al Congreso por la circunscripción de Álava, en la que había cosechado un sonado fracaso. El atropellado empadronamiento en Segovia no impidió que se valorara esta decisión como una maniobra cuando menos extraña. El Grupo Socialista en las Cortes de Castilla y León, por cierto, votó en contra de la designación de Maroto, dos meses después de impugnar el veto de su candidato en el Parlamento de Cataluña. Véase https://bit.ly/ 33JS7UV. 
designación de los senadores. Otra de las tendencias que se pueden observar se refiere al perfil político y/o profesional de los senadores de designación autonómica. Se ha lamentado que no ha existido voluntad política para proponer a senadores con perfiles más cercanos a la realidad territorial y que, una vez electos, tampoco adquieren dicho perfil (Tudela Aranda, 2017: 22). Sin embargo, desde 2015 se ha podido constatar que la extracción de la mayoría de senadores de designación autonómica revela un perfil político muy destacado en el ámbito de la comunidad autónoma y, además, una que vez en el Senado suelen participar directamente en las funciones de dirección e impulso de la Cámara, ocupando cargos importantes (Garrote, 2017: 87-88).

Esta tendencia a la especialización y profesionalización de los senadores obedece también en cierto modo a la desaparición de la necesaria vinculación del cargo de senador de la condición de diputado autonómico. Ello ha favorecido la formalización de un régimen de relaciones entre los senadores y sus parlamentos regionales que a priori son de difícil categorización jurídica.

Diez comunidades autónomas contemplan algún mecanismo de relación entre los senadores autonómicos y la Asamblea designante, con más o menos precisión en su regulación. Lógicamente, las cuatro comunidades autónomas que exigen ostentar la condición de diputado autonómico no prevén ningún tipo de enlace posterior, habida cuenta de la pertenencia del senador a la Cámara autonómica. Así, salvo Asturias, Galicia y Navarra — cuya normativa de designación ha permanecido sin apenas modificaciones desde los años ochenta-, el resto de comunidades autónomas han establecido reglas para garantizar la vinculación de sus senadores.

Dada la heterogeneidad de fuentes y contenidos se puede considerar un doble parámetro de análisis: si los preceptos que prevén dichas relaciones se encuentran suficientemente desarrollados para poder ser aplicados, y si los términos en los que se desenvuelven esas relaciones implican comparecencia personal ante algún órgano del Parlamento. Combinando ambos criterios es posible clasificar el régimen de relaciones en tres niveles (Garrote, 2017: 80-84). El primero incluiría las reglas denominadas «leves», por ausencia de desarrollo normativo o por configurar una vinculación más frágil. En ellas se incluyen las previstas en Castilla y León, Murcia y País Vasco ${ }^{16}$, donde se les permite la asistencia voluntaria a las sesiones de la Cámara o se les puede requerir cierta información, pero que no implica la comparecencia personal. En un segundo nivel se situarían las disposiciones que prevén la posibilidad de que los senadores acudan personalmente a informar o bien de su actividad en

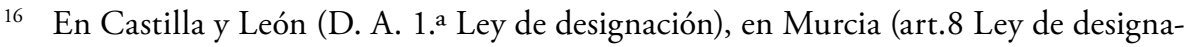
ción), y en el País Vasco (art. 233 Reglamento del Parlamento) 
el Senado, o bien acerca de un asunto de interés y relevancia para las materias incluidas en el orden del día del Pleno. La limitación estricta del objeto de la información (Castilla-La Mancha) ${ }^{17}$ o la falta de desarrollo reglamentario (Andalucía) ${ }^{18}$ sitúan a estos regímenes en un punto medio. Por último, en el máximo nivel se encuentra la normativa que denominamos «dura», bien porque se encuentra más desarrollada a nivel legal o reglamentario y que pormenorizadamente detalla las comparecencias de los senadores, o bien porque se contemplan las mismas como obligatorias. Así, regulan en detalle las comparecencias Aragón ${ }^{19}$, Canarias ${ }^{20}$ y Comunidad Valenciana ${ }^{21}$.

Por su parte Baleares ${ }^{22}$ y Cataluña ${ }^{23}$ poseen la regulación más rígida al considerar obligatorias las comparecencias.

17 Art. 100.1 del Reglamento de la Cámara.

18 El art. 223 del Estatuto de Autonomía de Andalucía señala que los senadores elegidos o designados por Andalucía podrán comparecer ante el Parlamento en los términos que establezca su reglamento para informar de su actividad en el Senado.

19 Art. 12 de la Ley de designación de Aragón y art. 243 del Reglamento de las Cortes de Aragón. Resolución de la Presidencia de las Cortes de Aragón, de 20 de noviembre de 2013.

20 Art. 204 Reglamento parlamentario de Canarias.

21 Una vez que la STC 123/2017, de 2 de noviembre, ha declarado inconstitucional la obligatoriedad de las comparecencias de los senadores, la normativa valenciana vigente es la que contemplaba el art. 16 de la Ley 9/2010, de 7 de julio, que señala que las Comisiones y los grupos parlamentarios podrán solicitar comparecencias de los senadores ante las comisiones de la Cámara para informar sobre temas relacionados con su actividad parlamentaria de interés para la Comunitat Valenciana.

$22 \mathrm{El}$ art. 50 del EA de Baleares establece que los senadores «comparecerán ante la comisión parlamentaria pertinente a iniciativa propia o a requerimiento de un grupo parlamentario o de una quinta parte de los Diputados para informar de su actividad en el Senado en los términos que establezca el Reglamento del Parlamento de las Illes Balears». El art. 189.8 del Reglamento del Parlamento reproduce el precepto estatutario.

23 En Cataluña, el art. 179 de su EA señala: «Los senadores elegidos en Cataluña y los que representan a la Generalitat en el Senado pueden comparecer ante el Parlamento a petición propia para informar sobre su actividad en el Senado, en los términos que establece el Reglamento del Parlamento». La Ley de designación (art. 9) añade: «2. El Parlamento puede solicitar la comparecencia de los senadores que representan a la Generalidad en el Senado de acuerdo con lo establecido por el Reglamento del Parlamento».

El Reglamento dispone en el art. 172.3: «Los senadores que representan a la Generalidad en el Senado, a petición de la tercera parte de estos o por acuerdo de la comisión, deben comparecer en una sesión informativa para informar de sus actuaciones en el 
En definitiva, parece que se han generalizado las previsiones de comparecencia de los senadores con mayor o menor grado de concreción y obligatoriedad. Junto con ello, no debemos ignorar que también se contemplan una serie de derechos y facultades para estos senadores, como la posibilidad de intervenir en la Asamblea o que les sean notificados los asuntos tratados en la misma. Todo ello parece configurar una suerte de estatuto jurídico del senador designado como un conjunto de derechos y deberes cuya trascendencia jurídica está por ver, pero que sin duda no comparten con los senadores electos ${ }^{24}$.

En todo caso, las previsiones normativas no siempre han tenido eco en la práctica parlamentaria y han sido muy escasas las comparecencias. Como afirma Tudela Aranda (2017: 18), «de forma prácticamente generalizada, no se ha transcendido de la norma a la realidad». A veces por la falta de desarrollo normativo de las previsiones legales, como en el caso de Andalucía ${ }^{25}$. En otros casos, las comparecencias se han solicitado, aunque no se han celebrado finalmente. En Aragón, se solicitó la comparecencia de la senadora Luisa Fernanda Rudi, aunque para un asunto que nada tenía que ver con su actividad en el Senado, sino con los sueldos que percibe ${ }^{26}$. En Valencia, también se solicitó la comparecencia de la senadora Rita Barberá, con un objetivo ajeno a su labor como senadora (dar explicaciones sobre la operación Taula), y ella manifestó su negativa a comparecer ${ }^{27}$.

No obstante, sí se han celebrado comparecencias en el Parlamento de Illes Balears, aunque el motivo de la comparecencia no fuera de interés autonómico. Así, el senador Antich tuvo que comparecer para explicar la

Senado respecto a cualquier tramitación relacionada con la Generalidad o con las comunidades autónomas. 4. Los senadores deben ser informados de los acuerdos y debates del Parlamento relacionados con la actividad y las competencias del Senado».

24 Con la excepción de Andalucía y Cataluña, cuyos estatutos de autonomía prevén la posibilidad de comparecencia de todos los senadores, electos y designados, aunque el desarrollo posterior en el caso de Cataluña se haya centrado exclusivamente en los designados.

25 En junio de 2016, la senadora Maribel Mora (Podemos) solicitó comparecer ante el Parlamento andaluz y se le denegó por no estar contemplado en el reglamento. De hecho, en febrero de 2018 el grupo parlamentario Podemos presentó una proposición de reforma del reglamento parlamentario para incluir en el mismo un artículo en el que se regulasen las comparecencias de los senadores. Véase, Boletín Oficial del Parlamento de Andalucía, núm. 655, X legislatura, de 12 de marzo de 2018.

26 La solicitud de comparecencia, presentada por Podemos, fue calificada por la Mesa de las Cortes y se le dio traslado a la Mesa de la Comisión Institucional, pero no se llegó a celebrar antes de la disolución de las Cortes. Véase https://bit.ly/32M4ezA.

27 Véase https://bit.ly/2NHKF7q. 
ayuda prestada a ERC para formar grupo parlamentario ${ }^{28}$. También se solicitó la comparecencia del senador Bauzá para explicar su voto en contra de suprimir los aforamientos ${ }^{29}$, y la de ambos senadores para explicar su postura ante la aplicación del art. $155 \mathrm{CE}$ en Cataluña ${ }^{30}$. Precisamente, la aplicación del art. $155 \mathrm{CE}$ en Cataluña fue asunto que centró la comparecencia de los ocho senadores designados por el Parlament de Cataluña ante la Comisión de Asuntos Institucionales el 24 de octubre de $2017^{31}$.

Finalmente, queda por analizar uno de los aspectos que más debates doctrinales suscitó al principio, que fue el de la duración del mandato de los senadores de designación autonómica. La necesidad de conjugar lo dispuesto en el art. 69.6 CE con la vinculación del mandato de los senadores a la legislatura de la asamblea fue una de las cuestiones resueltas por la STC 40/1981. Así, el Tribunal sostuvo que las comunidades autónomas "pueden optar y efectivamente han optado dentro del marco de su autonomía [...] e independientemente de que sus senadores deban o no ser miembros de las respectivas asambleas legislativas, entre la vinculación del mandato senatorial con la legislatura de la Asamblea legislativa (Estatuto catalán y Ley Vasca 4/1981) o con la legislatura del Senado (Estatuto gallego)», por lo que, «en ausencia de una regulación constitucional sistemática, ambas opciones son constitucionalmente válidas».

La mayoría de las comunidades autónomas establecen la duración del mandato de los senadores vinculado a la legislatura de la Asamblea (bien directamente, bien indirectamente a través de la exigencia de la condición de diputado autonómico). Esta posibilidad fue criticada por Punset (1983: 182-185) por entender que conculcaba la prohibición de mandato imperativo del art. 67.2 CE y que el mandato debería finalizar en todo caso al término de la legislatura del Senado. La confirmación de los senadores designados tras la elección de un nuevo Senado, prevista en las normas autonómicas - , y cuya constitucionalidad fue también confirmada en la STC 40/1981—, tiende a soslayar la eventual quiebra del mandato de cuatro años de duración prescrito en el art. 65.6 CE. De modo que, pese a las reticencias doctrinales, esta cuestión no parece suscitar mayores problemas (García-Escudero, 1999), más allá de las posibles vacantes que pueden quedar sin cubrir en el intervalo que media entre la disolución de la Asamblea autonómica y la designación de los nuevos senadores (Marañón, 2018: 275-277).

\footnotetext{
28 Véase https://bit.ly/2q9xD9M.

29 Véase https://bit.ly/2qNsUKY.

30 Véase https://bit.ly/2KhTGlu.

31 Véase https://bit.ly/2O6z1BW. Se puede ver el vídeo de la comparecencia del senador Alegre en https://bit.ly/33HqJXW.
} 


\section{LA STC 123/2017: ¿̇LA REAFIRMACIÓN DEL ESTATUS TRADICIONAL DE LOS SENADORES AUTONÓMICOS?}

El recurso de inconstitucionalidad resuelto por la STC 123/2017, de 2 de noviembre, tenía como objeto la Ley 10/2016, de 28 de octubre, de modificación de la Ley 9/2010, de 7 de julio, de Designación de Senadores o Senadoras en Representación de Comunitat Valenciana. Tanto por las cuestiones suscitadas como por los argumentos esgrimidos por el Tribunal la sentencia está llamada a ser un referente — como es la STC 40/1981 — sobre la significación de los senadores de designación autonómica en el sistema político e institucional español.

\section{BREVE ANÁLISIS DE LA LEY 10/2016, DE 28 DE OCTUBRE}

Como se sabe, la controvertida reforma de la Ley 9/2010, de 7 de julio, de Designación de Senadores o Senadoras en Representación de la Comunitat Valenciana, tuvo como detonante el caso de la senadora Rita Barberá. En julio de 2015 la exalcaldesa de Valencia fue designada senadora por las Corts Valencianes, a instancias del Partido Popular. Cuando comenzaron a destaparse algunos casos de corrupción en los que presuntamente había participado, su partido le solicitó que se diera de baja del mismo y que renunciara al acta de senadora. Rita Barberá abandonó el Partido Popular pero mantuvo su escaño en el Senado, adscribiéndose desde ese momento al Grupo Mixto. La actitud de la senadora estaba amparada por la ley y por la reiterada jurisprudencia del $\mathrm{TC}$, que ha afirmado siempre que el escaño pertenece al representante y no al partido.

Sin embargo, el asunto tomó un cariz diferente cuando el grupo parlamentario de Podemos en las Corts Valencianes presentó una proposición de ley de modificación de la Ley 9/2010, de Designación de Senadores en Representación de la Comunidad Valenciana. Esta propuesta se presentó ante la incomparecencia de la senadora Rita Barberá ante la Comisión de Coordinación, Organización y Régimen de las Instituciones de la Generalitat de las Corts, donde estaba citada para dar explicaciones sobre su posible vinculación al caso Imelsa ${ }^{32}$. Durante la tramitación parlamentaria de la ley, que se

32 La diputada Fabiola Meco, del Grupo Parlamentario Podemos, solicitó a la mesa de las Corts que pidiese un informe a los servicios jurídicos de la Cámara en relación con la posibilidad de revocar a la senadora D. ${ }^{a}$ Rita Barberá Nolla. El informe de 1 de marzo, suscrito por el letrado Juan Antonio Martínez Corral, apuntaba que, «en 
realizó por el procedimiento de urgencia, se introdujeron algunas modificaciones al texto inicial y la ley finalmente contó con el apoyo de los grupos parlamentarios de Podemos, Ciudadanos, Compromís y Socialista (Fernández Esquer, 2017).

La Ley 10/2016, de 28 de octubre, consta de un artículo único integrado por siete apartados, una disposición transitoria única y una disposición final. Destaca el apartado segundo, que suprime las comparecencias previas de los candidatos a senador, así como el apartado quinto, que añade un art. 14 bis en el que se establece que las Corts «podrán revocar cualquier nombramiento conferido como senador o senadora en representación de la Comunitat Valenciana». Además, se regula el procedimiento de revocación con nueve apartados en los que se detallan los titulares de la iniciativa de revocación, causas, trámites y requisitos (un análisis en Navarro Marchante, 2018: 132-140; Pauner, 2019: 415-417). Baste aquí señalar que la solicitud de revocación debe ser propuesta por un mínimo de dos grupos parlamentarios que representen, al menos, una décima parte de los miembros de la Cámara. En la solicitud deben exponerse las causas que, a juicio de los proponentes, justifiquen la "pérdida de confianza», basada "en el incumplimiento de las obligaciones del senador o senadora establecidas en la actual ley así como actuaciones que comporten el desprestigio de las instituciones». Entre el incumplimiento de las obligaciones establecidas por dicha ley se encontraría la obligación de comparecer. Sin embargo, existe una peligrosa indefinición sobre qué ha de entenderse por "pérdida de confianza» derivada de «actuaciones que comporten el desprestigio de las instituciones», que deja abierta la posibilidad de plantear una revocación por razones políticas (Navarro Marchante, 2018: 137).

Para que la revocación sea efectiva se exige una mayoría cualificada de dos tercios de los miembros de las Corts y que en la votación no se registre ningún voto negativo de algún diputado que sea miembro del grupo parlamentario que en su día propuso al senador. Esta última previsión fue incorporada a petición del grupo Compromís (Fernández Esquer, 2017: 17).

El apartado séptimo modifica el art. 16 de la Ley 9/2010, que regula las comparecencias de los senadores ante la Asamblea designante. En sus tres apartados el artículo dispone: 1) que los senadores habrán de comparecer a petición de los grupos parlamentarios para informar sobre temas relacionados con la actividad parlamentaria; 2) al menos anualmente los senadores deben comparecer ante la Comisión de Coordinación, Organización y Régimen de

ausencia de una previsión legal expresa que lo autorice, comportaría una lesión del derecho fundamental reconocido en el art. 23.2 CE», lo que lo haría nulo de pleno derecho (Pérez Gabaldón, 2019: 432; Navarro Marchante, 2018: 131). 
las Instituciones para rendir cuentas de su trabajo en el Senado, y 3) se decreta el carácter obligatorio de las comparecencias.

Por último, la disposición transitoria única somete a «los senadores y senadoras designados conforme la regulación anterior a lo que establece la presente ley con excepción de las disposiciones relativas al procedimiento de nombramiento".

No es necesario insistir en que la posibilidad de revocación prevista en la ley fue acogida con estupor desde ciertos ámbitos políticos y con desconfianza dese el sector académico, y no sorprendió que fuera impugnada ante el Tribunal Constitucional.

\section{LA STC $123 / 2017$, DE 2 DE NOVIEMBRE}

Como era de esperar, la Ley 10/2016 fue recurrida ante el Tribunal Constitucional por senadores del Grupo Parlamentario Popular el 7 de febrero de 201733. La STC 123/2017 (ponente magistrado Xiol Ríos) resuelve el recurso de inconstitucionalidad que tenía como objeto los apartados uno, tres, cuatro, cinco y siete de la Ley 10/2016.

Los recurrentes basan su fundamentación en tres puntos. En primer lugar, la introducción por ley autonómica de una remoción de la condición de senador por la Asamblea que lo designó ajena a las previsiones constitucionales (art. 69.6 CE), estatutarias (art. 22.j EAV), del régimen electoral general (art. 165.4 LOREG) y del Reglamento del Senado (arts. 12 y ss.) y sustentada en un mecanismo de control interno de responsabilidad política. En segundo lugar, el establecimiento de una obligación de rendición de cuentas con carácter de deber que pesa sobre el senador autonómico y que es un control del ejercicio del cargo público. En tercer lugar, la pretendida retroactividad de la ley. En la argumentación se sostiene que el artículo único de la ley impugnada vulnera los arts. $23 \mathrm{CE}, 66.3 \mathrm{CE}, 67.2 \mathrm{CE}$, 69.6 CE, 70 CE, 71 CE y 81.1 CE. La disposición transitoria única se encuentra en abierta contradicción con los arts. 9.1 y $9.3 \mathrm{CE}$.

Por su parte, las alegaciones de la letrada de las Corts y del letrado de la Generalitat pueden resumirse en cuatro puntos. 1) No existe reserva de ley orgánica para regular todas las causas de cese de los senadores territoriales y,

33 El presidente del Gobierno también impugnó la citada ley en julio del mismo año, tras los infructuosos intentos de conciliación previstos en el art. 33.2 LOTC. La STC 141/2017, de 30 de noviembre, declara la pérdida del objeto de este recurso al haber sido ya resuelto mediante STC 123/2017. 
consecuentemente, las Corts disponen de competencia para completar las causas de cese de estos senadores dentro de los límites establecidos por la Constitución, la LOREG y el EAV. El art. 18 f) del Reglamento del Senado prevé entre las causas de cese de los senadores el establecimiento de otras adicionales por el legislador autonómico. Además, la jurisprudencia constitucional niega que las personas designadas por estos Parlamentos dispongan de un derecho constitucional a permanecer en el cargo durante cuatro años. 2) La ley respeta el principio de seguridad jurídica (art. 9.3 CE), pues no constituye la negación de ningún derecho, sino la frustración de una expectativa para los senadores designados; la ley no impone mandato imperativo alguno sino que prevé, de forma excepcional, por la concurrencia de causas taxativas y previamente determinadas, con todas las garantías y con una mayoría muy cualificada, que el órgano primario de representación de los valencianos estime que alguna de las personas que en su momento designó deben dejar de representarle por «incumplimiento de las obligaciones» previstas en dicha ley, así como por actuaciones que comporten el «desprestigio de las instituciones». Las co parecencias de los senadores ante las Corts son solo informativas y estaban ya previstas en la ley que se modifica, siendo norma general en el conjunto de las comunidades autónomas, en algunas de las cuales se impone de forma expresa esa obligación. El hecho de dar cuenta de la actividad no implica la imposición de determinada actividad al senador.

Ante este cúmulo de argumentaciones, lo primero que hace el Tribunal es acotar tanto el objeto del recurso como las normas que se tendrán en cuenta para su enjuiciamiento (FJ 2). Así, limita su análisis al apartado 5 del artículo único, que introduce el procedimiento de revocación en un nuevo art. 14 bis, y los números 2 y 3 del apartado 7 , que se refieren a la posible rendición de cuentas y a la obligatoriedad de las comparecencias.

En las consideraciones previas (FJ 3), el Tribunal recuerda que los senadores de designación autonómica cuentan con una "propia especificidad» pero «esta singularidad se ha de conciliar, en todo caso, con la esencial "igualdad de estatus" [...] entre unos y otros miembros de la Cámara, cualquiera sea su origen electivo, integrantes todos ellos por igual de las Cortes Generales». De este carácter propio proviene el hecho de que mediante «su designación las Comunidades Autónomas participan de modo directo en la integración de un órgano constitucional del Estado», siendo esa participación una «expresión, garantizada por la misma Constitución, de la autonomía política de aquellas» (FJ 3 A). Pero los senadores autonómicos «ostentan posición constitucional idéntica a la de los demás miembros de las Cortes Generales», lo que implica que son representantes del pueblo español en su conjunto - como unidad ideal de imputación-y no están vinculados por mandato imperativo (FJ 3B). 
De esta manera, estos senadores «incorporan también, por su origen, lo que cabría llamar quizá una determinada representatividad de la respectiva Comunidad Autónoma», pero ese aspecto hace referencia «solo al título por el que los designados acceden al escańo senatorial y no interfiere en la representación de todo el pueblo español a la que concurren en el Senado, como Cámara que forma parte de las Cortes Generales» (FJ 3B.a).

Del mismo modo, la prohibición de mandato imperativo recogida en el art. 67.2 CE, en relación con el art. 66.1, implica que la responsabilidad de diputados y senadores, política en todo caso, "pueda llegar a ponerse a prueba [...] a través de nuevos procedimientos de elección [...] o, por lo que ahora importa, de designación, no de otro modo». El mandato libre del art. 67.2 CE supone:

[...] la exclusión de todo sometimiento jurídico del representante, en cuanto tal, a voluntades políticas ajenas y proscribe por ello, en particular, que sobre él se hicieran pesar tanto instrucciones vinculantes en Derecho que pretendieran disciplinar su proceder, como asimismo cualquier tipo de sujeción, jurídicamente impuesta, a la confianza de sus electores (expresada del modo que se pretendiera) o de las organizaciones o grupos políticos en que se integre o en cuyas listas hubiera concurrido a las elecciones; sujeción que, de llegar a verificarse, contrariaría asimismo, adicionalmente, sus derechos al mantenimiento en el cargo y a ejercerlo sin constricciones ilegítimas (art. 23.2 CE) (FJ 3B.b).

Definidos así los parámetros de enjuiciamiento se pasa a examinar, por orden de intensidad creciente, la obligatoriedad de las comparecencias, la rendición de cuentas y la revocación.

Comienza afirmando el TC que las previsiones de comparecencias «son, de principio, inocuas desde el punto de vista de la constitucionalidad», siempre que se limiten a iniciativas parlamentarias con efectos jurídicos acotados a la vida interna de las Cámaras y sin alcance vinculante para el senador requerido. De hecho, ya existen normas de igual alcance en otras comunidades autónomas. Se reconoce que este tipo de reglas pueden favorecer el intercambio de información y facilitar una vía interparlamentaria para reforzar el principio de colaboración consustancial al Estado de las autonomías. No obstante, entiende que la ubicación normativa más adecuada sería el reglamento parlamentario (FJ 4A).

El Tribunal considera que a través de este tipo de reglas las comunidades autónomas ejercen «un concreto aspecto de sus competencias sobre la propia organización institucional». Sin embargo, «tales normas autonómicas no pueden, al hilo de semejantes previsiones, imponer deber de tipo alguno sobre 
aquellos senadores, miembros de un órgano constitucional del Estado por entero sustraído a las competencias de las Comunidades Autónomas».

En este sentido, se entiende que el precepto en cuestión se ha dictado «sin sustento en competencia autonómica alguna y es ya, solo por ello, contrario al propio Estatuto de Autonomía y, en consecuencia, inconstitucional». Apoya dicha argumentación en dos razones: en primer lugar, las normas autonómicas no pueden disciplinar, sin más, el régimen de los senadores designados, los cuales, conforme al art. 69.5 CEy al art. 22 j) EAV quedan parcialmente sometidos al ordenamiento jurídico estatutario solo en lo que hace a «las condiciones y modalidades de su designación» (STC 40/1981, FJ 1e). Por lo tanto, la normativa autonómica se debe limitar a regular el modo de designación y solo eso.

En segundo lugar, no "cabe en modo alguno parangonar [...] una ley autonómica con un Estatuto de Autonomía, aprobado este último mediante una ley orgánica del Estado». En este sentido, la objeción de inconstitucionalidad sería más formal que material, pues, como reconoce el propio Tribunal, «no ha de pronunciarse ahora sobre si la norma que así hemos de declarar inconstitucional no lo hubiera sido de haber estado contenida en el Estatuto de Autonomía para la Comunidad Valenciana» (FJ 4B).

El examen de la comparecencia anual de los senadores «para rendir cuentas de su trabajo en el Senado» concluye con su inconstitucionalidad tanto en atención a consideraciones competenciales como sustantivas. Respecto a las primeras, reitera lo dicho anteriormente sobre la ausencia de base estatutaria alguna.

En cuanto a las consideraciones sustantivas, al Tribunal le parece evidente la contradicción material con la Constitución (art. 67.2), pues «sitúa a estos senadores en una inequívoca situación de subordinación a la asamblea, o de dependencia política de la misma, al modo de la relación fiduciaria que vincula a un gobierno parlamentario. [...]. Se trata, en definitiva, de un precepto que solo podría haber sido establecido por la Constitución misma, no por ninguna otra fuente, estatal o autonómica, a ella subordinada». Concluye que no se puede, sin vulnerar la Constitución, someter «la actuación del senador al escrutinio y fiscalización de la asamblea y transformando así el libre mandato político que ostenta aquel en lo que constituye, sin más, su contrario, es decir, en una figura próxima, si no idéntica, al mandato de Derecho privado" (FJ 5).

Finalmente se aborda el examen de la revocación, realizando con carácter previo dos aclaraciones sobre la naturaleza de tal revocación y sobre el procedimiento para su aprobación. La revocación se configura «genuinamente, como una libre potestad de la Cámara». Y aunque se diga que está "fundamentada», 
lo cierto es que se lleva a cabo «sin sujeción a reglas que determinen objetivamente la resolución final». El Tribunal advierte sobre la indefinición de términos como «desprestigio de las instituciones», o el incumplimiento de las «obligaciones», y concluye que a la postre lo que la ley configura es una «relación fiduciaria» como la que se establece entre una Asamblea y un Gobierno responsable ante ella (FJ 6A.a). Y en cuanto al procedimiento, tal y como está regulado en la ley, confiere al grupo político del que proviene el senador una suerte de derecho de «veto", inaceptable si se tienen en cuenta los actos que han sido declarados inconstitucionales por contravenir el art. 23.3 CE, ya desde la STC 5/1983, de 4 de febrero, "por vincularse en ellos el mantenimiento en su cargo del representante a la voluntad del partido en cuyas listas concurrió a las elecciones» (FJ 6A.b).

Nuevamente, en este caso, encuentra el Tribunal contradicción de carácter competencial y sustantivo. Contradicción competencial porque ni siquiera el Estatuto de Autonomía podría imponer «cualesquiera deberes o controles sobre los miembros de órganos constitucionales del Estado». La potestad de las comunidades autónomas:

[...] se cińe a la designación, en cada legislatura autonómica, de estos senadores [...] al posible establecimiento a tales efectos [...] de algunas condiciones e incompatibilidades adicionales a las definidas en la Constitución o en la legislación electoral general y, en fin, a la eventual previsión, en ejercicio de las competencias sobre la propia organización institucional (art. 49.1.1 EAV), de solicitudes parlamentarias de información a los senadores ya designados.

En este sentido, no cabe comparar «el cese del designado por pérdida sobrevenida de alguna de tales condiciones adicionales (por ejemplo, por dejar de ser diputado autonómico)» con la revocación que se examina (FJ 6B).

Desde el plano sustantivo, la revocación prevista en la ley, "genuina responsabilidad política, por "pérdida de confianza" del senador ante la asamblea autonómica» entra en abierta contradicción con los arts. 67.2 y 66.1 CE. La interdicción del mandato imperativo se contradice con la "pretendida vinculación del senador a la "confianza" de la Cámara que en su día lo designó" y con la "previsión, notoriamente inconstitucional, de que la asamblea pueda, al retirarle tal confianza, provocar su remoción del cargo representativo».

No existe tampoco justificación constitucional para la revocación en la circunstancia de que los senadores autonómicos sean de elección «indirecta», pues la «prohibición del mandato imperativo se establece [...] para todos los miembros de las Cortes Generales, sin distinción». Además, los titulares de cargos representativos de elección indirecta «siguen siendo representantes populares» (FJ 6B). 
Y para mayor abundamiento, el Tribunal contempla también la vulneración del art. 23.2 CE. «Los preceptos enjuiciados comportan todos ellos [...] una perturbación ilegítima en el ejercicio del cargo de senador», además de «la inconstitucional posibilidad de remover del escaño a su titular, medidas todas que infringen también lo dispuesto en el artículo 23.2 CE» (FJ 7).

La decisión del Tribunal Constitucional, declarando la inconstitucionalidad de todos los apartados recurridos, fue, sin duda, la esperada. En la sentencia, de indudable valor doctrinal, se clarifican muchos aspectos sobre el estatus de los senadores de designación autonómica. Resulta lógico. Prácticamente desde la STC 40/1981 el TC no había tenido ocasión de abordar en control de constitucionalidad la regulación de los senadores autonómicos en términos tan amplios.

De la sentencia se pueden extraer algunas certezas, pero también siembra ciertas dudas. En orden inverso a como se ha desarrollado la sentencia, podemos decir que la zona de certeza se sitúa en la inconstitucionalidad de la revocación del senador, por abierta contradicción con el art. 67.2 CE. Incluso en ausencia de ese artículo (como sucede en el ámbito municipal), la remoción de los cargos representativos vulnera descaradamente el art. 23.2 CE, como viene sosteniendo el Tribunal desde la STC 10/1983, aunque referida a la posición dominante de los partidos con respecto a sus representantes. No obstante, la rotundidad de los argumentos del Tribunal podría haberse acompañado, también, de alguna referencia a la representación política contemporánea con las características propias del momento actual. La crisis de la representación política, el alejamiento entre electores y elegidos, la conducta no siempre ética de los representantes, el transfuguismo, las deslealtades al electorado y, en fin, los desafíos ante los que se enfrenta la democracia actual, globalizada, digital, líquida..., todos ellos son problemas a los que el sistema constitucional, en su interpretación más clásica, no puede dar una respuesta satisfactoria. El TC llegó a considerar que, en abstracto, la posibilidad de revocación de los representantes por parte de los representados no plantea contradicción teórica con los postulados de la democracia representativa, pero recordó que en el sistema constitucional español la prohibición contenida en el art. 67.2 CE impide articular dicho mecanismo para los miembros de las Cortes Generales (STC 10/1983, FJ 2). Siendo esto así, no cabe duda de que algo no encaja en el circuito representativo. Los ciudadanos tienen muy limitada la capacidad de elección de sus representantes (listas cerradas y bloqueadas, pésima democracia interna en los partidos y la designación de los senadores totalmente entregada a una opaca negociación partidista). Pero tampoco cuentan con mecanismos que permitan reforzar la responsabilidad de los electos. El sistema a veces no permite castigar a quienes ya no gozan de la confianza del 
electorado. El mandato de los representantes es un cheque en blanco de los electores, pero al mismo tiempo está absolutamente comprometido con las directrices de los partidos políticos. La interpretación del mandato libre podría haberse ajustado, aunque sea mínimamente, a la evolución que ha registrado el sistema democrático español.

En la zona intermedia podemos situar la valoración que hace el Tribunal sobre la comparecencia para rendir cuentas. Evidentemente, se ha considerado que el precepto, al prever una comparecencia anual para «rendir cuentas», permite anudar algún tipo de consecuencia jurídica ante la valoración que se haga de dicho escrutinio, que puede desembocar incluso en la revocación. Es cierto que un análisis conjunto y sistemático de la ley puede llevar a esa conclusión, sobre todo por la utilización de un término tan contundente como «rendición de cuentas», pero podría tener un alcance diferente si esa comparecencia anual se contemplara como un trámite de información más. No en vano, el mismo Tribunal señala que las comparecencias informativas «podría[n] dar lugar, en pura hipótesis, a controversias o a críticas, de estricto alcance político, sobre su actuación en el Senado. De llegar esto a verificarse, no excedería, desde luego, de lo que es inherente al libre debate parlamentario» (FJ 5). En este caso, queda la duda de saber si solo es inconstitucional la rendición de cuentas como mecanismo de exigencia de responsabilidad con consecuencias jurídicas o si, por el contrario, la supervisión a efectos meramente informativos y con eventuales consecuencias políticas podría encajar en nuestro marco constitucional.

Por último, las comparecencias obligatorias se sitúan en la zona de incertidumbre. Parece claro que la ley autonómica, sin apoyatura en el estatuto de autonomía, no puede establecer como obligatorias las comparecencias de los senadores. Pero ¿̇sería compatible con la Constitución si esa obligatoriedad se fijara en el estatuto de autonomía? Este es el caso de Baleares. ¿Y en el reglamento parlamentario? Este es el caso de Cataluña. El Tribunal no lo deja claro y tampoco ofrece razones sustantivas como para descartar esa posibilidad. La heterogeneidad de fuentes normativas que regulan la figura de los senadores autonómicos requiere aportar referencias seguras sobre lo que puede regular el legislador y lo que no.

Si la finalidad de la comparecencia es meramente informativa y se refiere a alguna cuestión de interés autonómico que se encuentre tramitando en el Senado no encontramos ninguna causa que justifique su inconstitucionalidad. Del mismo modo que nadie ha discutido las facultades y derechos que se atribuyen a estos senadores (como acudir a las sesiones de las Comisiones o del Pleno, intervenir y recibir información) y que podrían plantear dudas al no ser miembros de la Cámara, tampoco debería objetarse que se esperara de estos 
senadores una actitud colaborativa. Se menciona en la sentencia que estas reglas forman parte de las competencias sobre la propia organización institucional. Precisamente, las alusiones que hace el Tribunal a la utilidad que tienen estas prácticas para fortalecer las relaciones de colaboración dan pie a pensar en que es el art. 69.1, que caracteriza al Senado como cámara de representación territorial, el que podría ser el principio-marco sobre el que proyectar estas comparecencias. El Tribunal ya "elevó a categoría de principio» el art. 69.1 cuando en al STC 40/1981 avaló la ley vasca que vinculaba el mandato de los senadores a la legislatura del Parlamento autonómico (Punset, 1983: 183). De hecho, parece que en esta ocasión el Tribunal no ha sido tan proclive a interpretaciones audaces como en 1981 y ha preferido mantenerse sobre seguro, reafirmando las categorías clásicas con ortodoxia, coherencia y determinación.

\section{REFLEXIONES FINALES EN TORNO A LA FIGURA DEL SENADOR AUTONÓMICO Y POSIBILIDADES DE APERTURA}

Si en algún momento se ha podido llegar a pensar que los senadores de designación autonómica podrían ser — si no lo eran ya- algo diferente al resto de parlamentarios; que su extracción, elección y modo de desempeño del cargo brindaban unas posibilidades de actuación originales y provechosas y que, a la postre, podrían ser el germen de una cierta representación territorial en el Senado, esta sentencia viene a rebajar bastante las expectativas. Los senadores de designación autonómica son iguales a los demás senadores en casi todo. Y en lo que no lo son (su modo de designación) la experiencia reciente muestra una tendencia a utilizar este mecanismo como moneda de cambio en las negociaciones políticas de los partidos, cuando no es utilizado como vía de escape para proporcionar a miembros del partido un escańo que no han conseguido obtener mediante la elección directa. No parece que esa fuera la intención del constituyente cuando se previó este peculiar régimen de designación. Se da la paradoja de que, mientras que el sistema electoral de los senadores provinciales permite a los electores el más amplio margen de elección, ofreciendo la posibilidad de personalizar el voto en los candidatos deseados, el sistema previsto para los senadores autonómicos es el más alejado de la voluntad de los electores. Y no precisamente por ser una elección indirecta. En esta función de designación no ha sido la normativa sino la práctica política la que en ocasiones ha desvirtuado el proceso. Si las cúpulas partidistas poseen un control extraordinario en la determinación de las candidaturas, ese poder aumenta aún más en la designación de senadores, que no pasan ni por el mínimo filtro de las urnas y 
que, gracias a la costumbre parlamentaria de aceptar los candidatos propuestos por los grupos, les permite presentar a los candidatos a su antojo. Una muestra de hasta qué punto se ha desvirtuado el proceso es el "caso Iceta». La dimisión de José Montilla, absolutamente legítima, estuvo motivada por la necesidad de conseguir que Miquel Iceta accediese al Senado nada menos que para presidir la Cámara. Estas estrategias políticas se pueden mover en el terrero de la legalidad, pero evidencian un rumbo errático y, a mi juicio, fuerzan decisiones muy relevantes sin recibir la aceptación de los ciudadanos.

No obstante, existe un amplio terreno en el que los senadores autonómicos podrían ser diferentes, sin dejar de ser iguales. Desde luego, habría que partir de su especial representatividad, que, sin llegar a ser «superior» a la de los provinciales, sí posee una legitimidad cualitativamente diferente (Aja y Arbós, 1980: 64; Ripollés, 1993: 105).

Es interesante comprobar cómo parte de la doctrina y cierta jurisprudencia de los primeros años ochenta apostaban por asignar a este grupo de senadores un papel específico en el desenvolvimiento del Estado de las autonomías y en ellos depositaban sus esperanzas de que en algún momento el Senado fuese algo parecido a una Cámara de representación territorial. Aja y Arbós (1980: 63) defendieron sin ambages esta lectura federalizante porque es "más acorde con la sistemática global de la Constitución, que define a las autonomías como uno de los rasgos esenciales de nuestro Estado». La temprana regulación de los senadores designados en el País Vasco, en la que ya se preveían mecanismos de colaboración, fue no solo avalada por el TC sino también vista como un ejemplo a seguir para el resto de comunidades autónomas (Saiz Arnaiz, 1985: 158).

El desarrollo normativo posterior de la figura del senador autonómico posibilita la creación de «un conjunto de relaciones entre las distintas instituciones parlamentarias imbricadas en la organización territorial» (Tudela Aranda, 2017: 6). Las normas vigentes ofrecen estas posibilidades, pero es necesario un impulso político para que verdaderamente cumplan la finalidad que persiguen. Para ello, además de una decidida voluntad política, sería conveniente interpretar las diferentes disposiciones con una renovada perspectiva territorial. Y ello, pese a las dudas que puedan surgir tras la STC 123/2017.

Las relaciones que pueden mantener los senadores designados con sus Cámaras autonómicas pueden reforzarse pese a la prohibición del mandato imperativo ${ }^{34}$. Un enfoque finalista de las normas que regulan el Senado en la

34 En opinión de Núñez Rodríguez (1998: 91), la negación de toda posibilidad instrumental y orgánica de intensificación de las relaciones de los senadores designados con sus asambleas de origen sería hipertrofiar la interpretación del mandato imperativo. 
Constitución permite afirmar que con estos senadores se buscaba trasladar las sensibilidades autonómicas a una Cámara de ámbito estatal, dando a estos representantes un perfil diferente.

Las comparecencias de los senadores en las Cámaras designantes ofrecen un potencial que no conviene desaprovechar. Visiedo Mazón (2002: 290) apostaba por incrementar los mecanismos de relación y convertir en periódicas las comparecencias. Esta propuesta permitiría sortear los recelos que pueden suscitar las comparecencias a petición de los grupos o por decisión de la Mesa. Además, convirtiendo este instrumento en una práctica rutinaria se evitaría someterlo a decisiones políticas de carácter coyuntural, como ha sucedido con frecuencia hasta ahora.

En definitiva, ante las probables transformaciones en la dinámica parlamentaria tanto nacional como autonómica, y conscientes de la dificultad de abordar reformas de calado, parece interesante profundizar en las posibilidades que estos senadores, diferentes pero iguales, pueden ofrecer en las relaciones interorgánicas y en la cooperación necesaria en el Estado autonómico.

\section{Bibliografía}

Aja, E. y Arbós, X. (1980). El Senado, Cámara posible de las Autonomías. Revista de Estudios Politicos, 17, 27-66.

Alberti Rovira, E. (2004). La representación territorial. Fundamentos, 3.

Alonso de Antonio, J. A. (2005). Algunas propuestas para la reforma constitucional del Senado. Foro, 2, 359-407.

Asensi Sabater, J. y Sevilla, J. (1986). La designación de Senadores Autonómicos en la perspectiva de la territorialización del Senado. En Jornadas de Parlamentos Autónomos (pp. 107-119). Valencia: Cortes Valencianas.

Camaaño Rodríguez, F. (1991). El mandato parlamentario. Madrid: Congreso de los Diputados.

- (2018). Edmund Burke ha vuelto a morir (Parlamento y descentralización política). Teoría y Realidad Constitucional, 41, 59-82. Disponible en: https://doi.org/10.5944/ trc.41.2018.22117.

Consejo de Estado (2009). Informe del Consejo de Estado sobre las propuestas de modificación del Régimen Electoral General, 24 de febrero de 2009. Disponible en: https://bit. ly/2QgOmTo.

Cuenca, A. (2003). Los senadores designados por las Comunidades Autónomas. Asamblea, $1,143-167$.

De Carreras Serra, F. (1996). El Senado en la Constitución española. En F. Pau i Vall (coord.). El Senado, Cámara de representación territorial (pp. 25-37). Madrid: Tecnos.

Elizalde Pérez, J. (1989). Comentario al artículo 69 de la Constitución. En O. Alzaga (dir.). Comentarios a las Leyes Políticas. Tomo VI (pp. 131-230). Madrid: Edersa. 
Fernández Esquer, C. (2017). La posible inconstitucionalidad de la Ley 10/2016, de modificación de la Ley 9/2010, de designación de Senadores o Senadoras en representación de la Comunitat Valenciana. Comunicación presentada en el XV Congreso de la Asociación de Constitucionalistas de España. León, 30 y 31 de marzo de 2017. Disponible en: https://bit.ly/31M3wlB.

Fernández Segado, F. (1984). La construcción del Senado en el proceso constituyente. Revista de Estudios Políticos, 38, 63-125.

Fernández-Carnicero, F. (2006). La representación territorial: ¿representación política o representación de intereses? Teoría y Realidad Constitucional, 17, 331-336. Disponible en: https://doi.org/10.5944/trc.17.2006.6711.

García-Escudero, P. (1994). La Comisión General de las Comunidades Autónomas (Reforma del Reglamento del Senado). Revista de Administración Pública, 133, 485-499.

- (1995). Los senadores designados por las Comunidades Autónomas. Madrid: Cortes Generales; Centro de Estudios Constitucionales.

- (1999). La duración del mandato de los senadores designados por las Comunidades Autónomas. Estado de la cuestión. Revista de las Cortes Generales, 47, 158-165.

Garrido López, C. (2016). Pero... ¿puede ser el Senado una Cámara de representación territorial? Revista Española de Derecho Constitucional, 107, 75-116. Disponible en: https:// doi.org/10.18042/cepc/redc.107.03.

(2019). El Senado ante el enigma de la representación territorial. Madrid: Marcial Pons.

Garrote, M. (2017). Los Senadores de designación autonómica y la teoría de los vasos comunicantes. Panorámica actual y una reflexión para el futuro. Cuadernos Manuel Giménez Abad, 14, 71-91.

Gutiérrez Rodríguez, F. J. (2004). El debate sobre la reforma del Senado. Madrid: Secretaría General del Senado.

Lago, I. y Martínez i Coma, F. (2007). Incentivos distintos y comportamientos iguales: la fragmentación del sistema de partidos en las elecciones del Congreso y el Senado. Revista de Estudios Políticos, 135, 159-178.

Marañón, R. (2018). Los senadores de designación autonómica como instrumento de articulación de las relaciones entre Parlamentos. Corts: Anuario de Derecho Parlamentario, 31, 258-278.

Navarro Marchante, V. (2018). La revocación de senadores de designación autonómica. (la ley valenciana 10/2016 y la STC 123/2017). Revista de Derecho Político, 1 (101), 123-157.

Núñez Rodríguez, V. (1998). Los parlamentos autonómicos como foro de elección senatorial. En J. M. Vera Santos (coord.). El Senado como cámara de representación territorial y la función de los parlamentos autonómicos (pp. 83-100). Madrid: Dykinson.

Pauner Chulvi, C. (2019). La inconstitucionalidad de la revocación de Senadores de designación autonómica por la Ley valenciana 10/2016. En Una vida dedicada al Parlamento. Estudios en Homenaje a Lluís Aguiló I Lúcia (pp. 413-423). Valencia: Corts Valencianes. Penadés, A. y Urquizu, I. (2007). La reforma del Senado. Madrid: Fundación Alternativas.

Pérez Gabaldón, M. (2019). Los Senadores de designación autonómica en la Comunitat Valenciana a partir de la sentencia del Tribunal Constitucional 123/2017, de 2 de noviembre. En Una vida dedicada al Parlamento. Estudios en Homenaje a Lluís Aguiló I Lúcia (pp. 427-436). Valencia: Corts Valencianes. 
Punset, R. (1980). El concepto de representación territorial en la Constitución española de 1978. Revista del Departamento de Derecho Político, 7, 105-118.

- (1983). La designación de senadores por las Comunidades Autónomas (a propósito de la Sentencia del Tribunal Constitucional de 18 de diciembre de 1981). Revista Española de Derecho Constitucional, 8, 161-185.

Reviriego, F. y Núñez, M. (2006). Repertorio bibliográfico sobre el Senado. Teoría y Realidad Constitucional, 17, 449-474. Disponible en: https://doi.org/10.5944/trc.17.2006.6718.

Ripollés Serrano, R. (1993). La funcionalidad del Senado en el Estado de las Autonomías. Revista Española de Derecho Constitucional, 37, 91-126.

Rubio Llorente, F. y Álvarez Junco, J. (eds.) (2006). El informe del Consejo de Estado sobre la reforma constitucional. Texto del Informe y debates académicos. Madrid: Consejo de Estado; Centro de Estudios Políticos y Constitucionales.

Ruiz Robledo, A. (2019). La arbitrariedad del Parlament. Diario de Sevilla, 24-5-2019. Disponible en: https://bit.ly/2Oa54kl.

Sáenz Royo, E. (2012). Parlamento, Partidos y Estado Autonómico: sobre la conveniencia de suprimir el Senado. Revista de Derecho Politico, 85, 171-194. Disponible en: https://doi. org/10.5944/rdp.85.2012.10248.

Saiz Arnaiz, A. (1985). El Parlamento Vasco. Relieve constitucional, organización y funcionamiento. Revista de Estudios Políticos, 46-47, 151-182.

— (1995). El Senado y las Comunidades Autónomas. Revista Vasca de Administración Pública, 41, 293-322.

Tudela Aranda, J. (2017). El Senado y los Parlamentos autonómicos. Un reflejo de las debilidades cooperativas del Estado autonómico. Revista General de Derecho Constitucional, 24, 1-34.

Visiedo Mazón, F. J. (2002). La designación de senadores en la Comunidad Valenciana. Artículo 11.J) del Estatuto de Autonomía: las limitadas posibilidades de mejora a través de la reforma de la Ley de designación y del Reglamento de las Cortes Valencianas. Corts: Anuario de Derecho Parlamentario, 12, 269-304. 